\title{
Investigation of phase transformation in Fe microalloyed Ti6Al4V alloy during continuous heating process
}

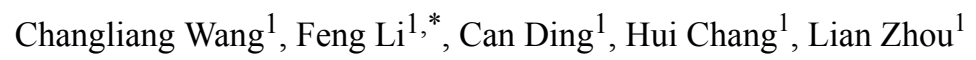 \\ 1. College of Materials Science and Engineering and Tech Institute for Advanced Materials, Nanjing Tech \\ University, Nanjing, 211816 \\ *fli@njtech.edu.cn
}

\begin{abstract}
$\underline{\text { Abstract }}$
The phase transformation and dilatometric curves in Fe microalloyed Ti6Al4V alloy (Ti6Al4V-Fe) during continuous heating at $1{ }^{\circ} \mathrm{C} / \mathrm{min}$ heating rate had been studied by dilatometer and metallographic methods, and $\beta$ phase transition temperatures of alloy were obtained. In order to validate the accuracy of these $\beta$ phase transition temperature and microstructure evolution, the relative phase concentration and the evolution of microstructure which were acquired by cooling after tempering were analyzed by metallographic microscope. The results illuminated that the expansion method was able to accurately measure the $\beta$ transformation temperature of Ti6Al4V-Fe alloy. The lathy-shaped $\alpha$ phase decreased significantly disappeared in the range of $838^{\circ} \mathrm{C}$ to $988^{\circ} \mathrm{C}$, and the $\alpha \rightarrow \beta$ phase transformation occurred.
\end{abstract}

Keywords: Ti6Al4V-Fe; Continuous heating process; Phase transformation; Microstructure evolution

\section{Introduction}

Ti6Al4V titanium alloy is one kind of attractive material for aerospace applications because of its high strength-to-density ratio, good hardenability and cold formability, excellent fatigue/crack propagation, and corrosion resistance ${ }^{[1]}$. However, due to the high processing cost of Ti6Al4V titanium alloy and the fact that its plastic toughness cannot meet the high requirements of structural parts, its use is limited. Recent studies have represented that adding a small amount of low-cost Fe element to Ti6A14V can significantly improve its processing performance and reduce processing cost [2]. Furthermore, with the increasing of the concentration of $\mathrm{Fe}$ in titanium alloy, the flow stress and deformation resistance drop significantly and thus increase the alloy's working suitability and lower the cost. This interesting result can cut the titanium alloy's working budget and is of great significance for the development of low-cost and high performance Ti6Al4V-Fe alloys. 
Solution treatment is an important process for improving the mechanical properties of titanium alloys [3]. In particular, the morphology and volume fraction of $\alpha$ precipitates, which significantly affect mechanical properties, are also related to phase transformation of alloys.More scholars have adjusted and controlled $\alpha$ phase structure of $\alpha+\beta$ titanium alloys such as Ti6A14V, TC11(Ti-6.5Al-3.5Mo-1.5Zr$0.3 \mathrm{Si}$ ) and $\mathrm{TC} 18(\mathrm{Ti}-5 \mathrm{Al}-5 \mathrm{~V}-5 \mathrm{Mo} 1 \mathrm{Cr}-1 \mathrm{Fe})$ by heat treatment, and obtained good matching of alloy strength and plasticity $[\underline{4-6}]$. The phase transition behavior in $\alpha+\beta$ titanium alloy is more complicated [7], especially for the investigation of Ti6Al4V-Fe alloy, because its phase transformation and microstructure evolution have yet to be studied further. In this present work, dilatometry method was used to study the $\alpha \rightarrow \beta$ phase transformation of Ti6Al4V-Fe titanium alloy during continuous heating, meanwhile, $\beta$ phase transition temperature of Ti6Al4V-Fe alloy was also obtained.

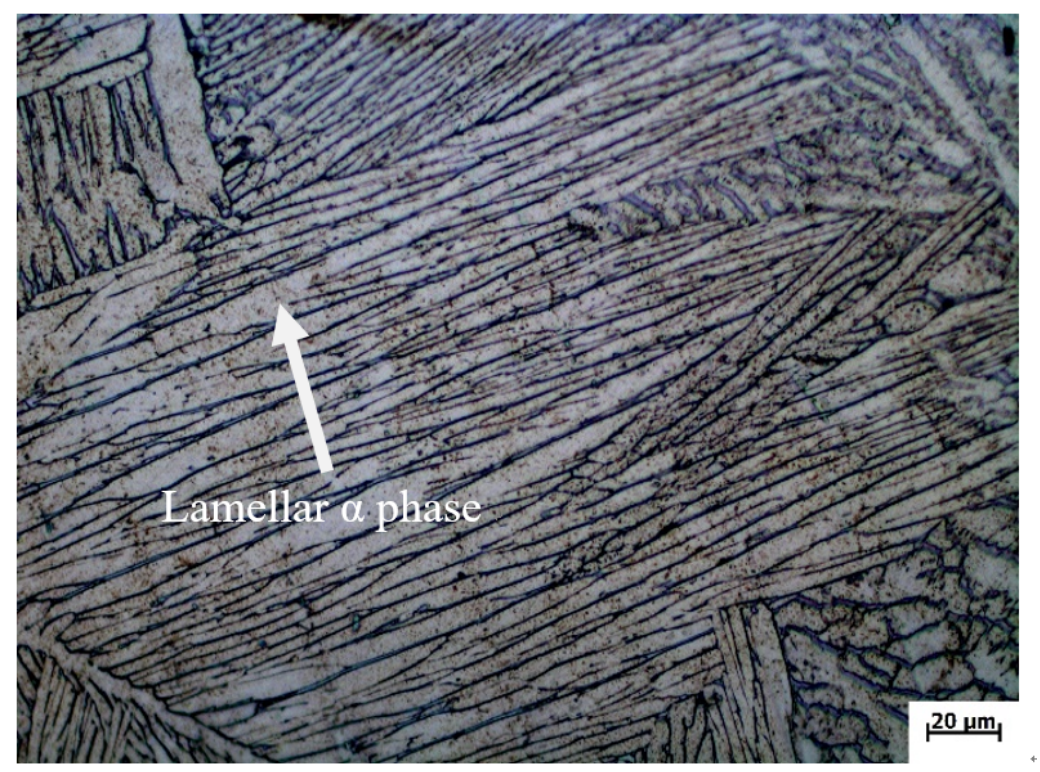

Fig.1 microstructure of Ti6Al4V-Fe alloy

\section{Experimental procedures}

The raw material used in the experiment was a hot-rolled Ti6Al4V-Fe plate with a thickness of 50 $\mathrm{mm}$, and its prefabricated structure is shown in Fig. 1. More obvious two-phase structure can be found from the metallograph. The microstructure at room temperature is a typical microstructure consisted by lathy-shaped $\alpha$ phase and $\beta$ phase. 
Dilatometry was conducted for the specimens with dimensions $25 \mathrm{~mm}$ in length and $5 \mathrm{~mm}$ in diameter by a computer-controlled horizontal pushrod dilatometer (Netzsch ${ }^{\circledR}$ DIL402C) with a high-resolution displacement transducer. The specimens for dilatometry were precisely machined via electrical discharge machining and mechanically polished to remove the re-cast layer. Testing was performed under high purity Ar flow ( $\geq 99.999 \%$ ). The specimens were placed in contact with the pushrod and heated at a rate of $1 \mathrm{~K} / \mathrm{min}$ up to $1100 \mathrm{~K}$. Changes in the length of the specimens with temperature were recorded and used to determine the linear thermal expansion.

The metallographic specimens were heated at a normal heat treatment furnace at the heating rate of 1 $\mathrm{K} / \mathrm{min}$, and then water quenched at different temperature, therefore, the untransformed phase could maintain until to room temperature, and it could be easily distinguished from the microstructure. The microstructures were observed by optical microscope (OM). The specimens for OM were prepared by rough and fine polishing followed by etching with 10 vol. $\% \mathrm{HF}, 20$ vol. $\% \mathrm{HNO}_{3}$ and 70 vol. $\% \mathrm{H}_{2} \mathrm{O}$. The phase content was determined by image-pro-plus software.

\section{Results and discussion}

\subsection{Dilatometric analysis}

Dilatometry curve and derivative curve at heating rate of $1 \mathrm{~K} / \mathrm{min}$ are shown in Fig.2. Along with the temperature increases, the alloy expansion rate was approximate to linear when the temperature is less than $838^{\circ} \mathrm{C}$, and then there was a slight increase in the dilatation law from 838 to $988^{\circ} \mathrm{C}\left(\mathrm{T}_{\mathrm{A}}\right.$ to $\left.\mathrm{T}_{\mathrm{B}}\right)$, which is caused by $\alpha \rightarrow \beta$ phase transformation. The dilatometry experiment displayed that the $\alpha \rightarrow \beta$ phase transformation was associated with a volume contraction of about $0.17 \%$ in pure titanium $[\underline{8}]$. In $\alpha+\beta$ titanium alloy, the overall expansions were obtained from the expansions of the two individual phases and their relative fractions in the microstructure. In summary, it can be concluded that, with the temperature of the Ti6Al4V-Fe alloy rises, a $\alpha \rightarrow \beta$ phase transition occurs in the temperature range of $838-988^{\circ} \mathrm{C}$, meanwhile, it can be said that the transformation is basically completed when the temperature reaches $988^{\circ} \mathrm{C}$ and the corresponding temperature can be considered as $\beta$ phase transition temperature. 


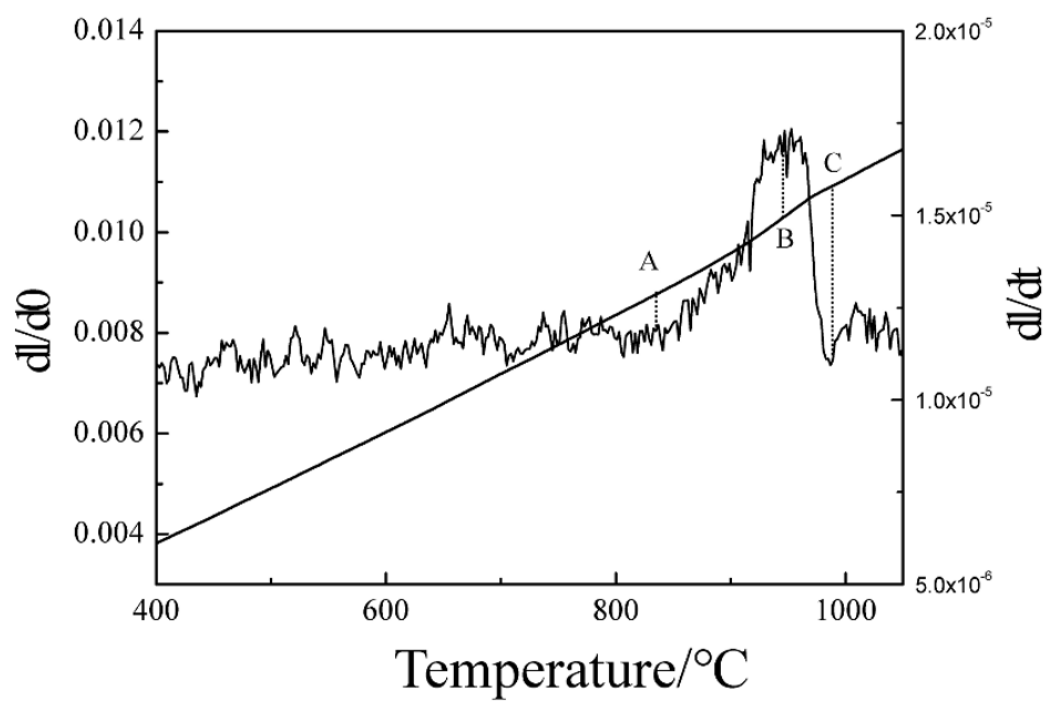

Figure 2 Dilatometry curve and derivative curve at heating rate of $1 \mathrm{~K} / \mathrm{min}$

\section{2 phase transition temperature}

Fig. 3 represents the $\mathrm{OM}$ structures obtained by cooling at 985 and $990{ }^{\circ} \mathrm{C}$ at a heating rate of $1{ }^{\circ} \mathrm{C} / \mathrm{min}$. It can be found that the quenched structure after $985^{\circ} \mathrm{C}$ still contain a small amount of lamellar $\alpha$ phase, and the $\alpha$ phase has completely disappeared at $990^{\circ} \mathrm{C}$, and we can obtain all the martensite structure. Therefore, the phase transformation temperature, $\mathrm{T}_{\beta}$, of Ti6Al4V-Fe alloy obtained by the metallographic method is between 985 and $990^{\circ} \mathrm{C}$, and the phase transition temperature $\mathrm{T}_{\beta}$ obtained by the dilatometer method is $988^{\circ} \mathrm{C}$. It can be concluded that phase transition temperature obtained by dilatometer method is very close to the one obtained by the metallographic method, which indicates that the phase transition temperature $\mathrm{T}_{\beta}$ obtained by the dilatometer method is true and reliable.

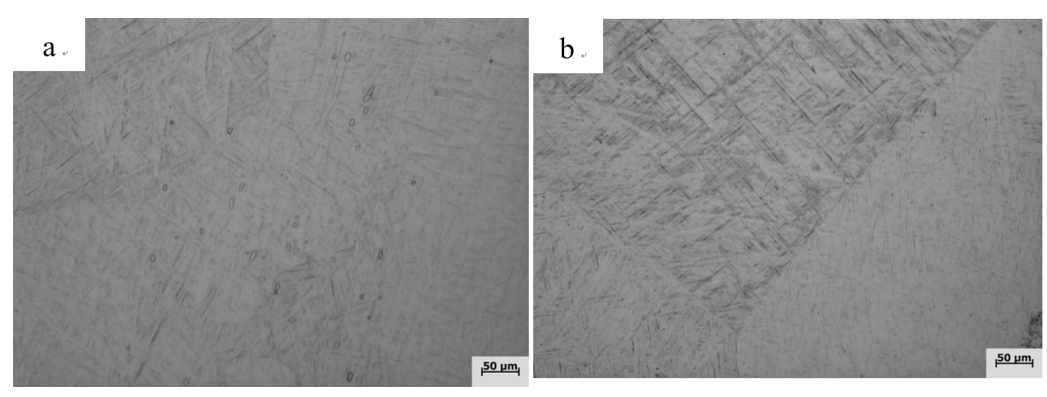




\section{Fig.3 OM images of Ti6Al4V-Fe alloy quenched at $1^{\circ} \mathrm{C} / \mathrm{min}$ heating rate}

\section{(a) $985^{\circ} \mathrm{C} ;$ (b) $990^{\circ} \mathrm{C}$}

\subsection{Microstructure evolution}

The $\alpha \rightarrow \beta$ phase transformation in the Ti6Al4V-Fe alloy during continuous heating can be identified by quenching the specimens at different temperatures. Three Ti6Al4V-Fe alloy samples (Samples 1, 2, and 3) were obtained based on the dilatometric curve measurement of the Ti6Al4V-Fe alloy at the heating rate of $1^{\circ} \mathrm{C} / \mathrm{min}$. These three specimens were heated continuously to 838,953 and $988{ }^{\circ} \mathrm{C}$ at $1{ }^{\circ} \mathrm{C} / \mathrm{min}$, respectively, and then immediately quenched. OM images of the three samples are illuminated in Fig.4. The sample 1 microstructure mainly consists of $\beta$ phase and large number of lathy-shaped $\alpha$ phase (Fig. 4a) when it was heated to $838^{\circ} \mathrm{C}$. The volume fraction of lathy-shaped $\alpha$ phase significantly reduced as the heating temperature increases. When Samples 2 and 3 were heated to 953 and $988^{\circ} \mathrm{C}$, the lathy-shaped $\alpha$ phase gradually transformed to $\beta$ phase (Fig. $4 \mathrm{~b}$ and $4 \mathrm{c}$ ). Thus, we conclude that $988^{\circ} \mathrm{C}$ is considered as the finishing temperature of $\alpha \rightarrow \beta$ phase transformation in the Ti6Al4V-Fe alloy during continuous heating.
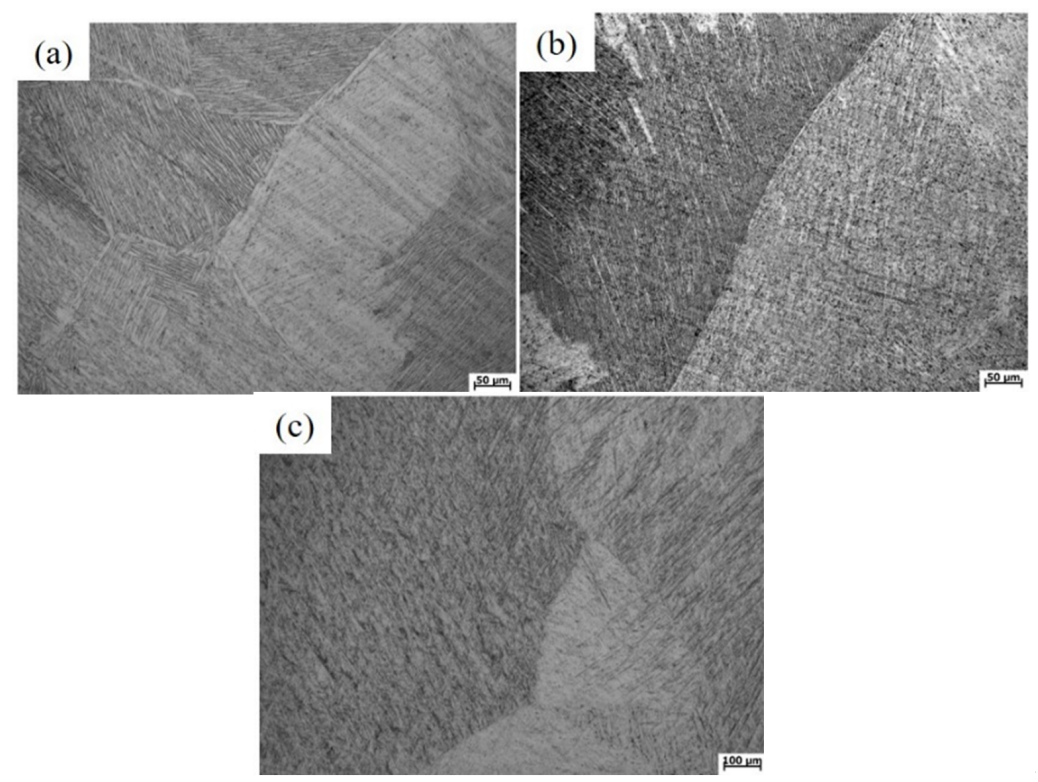

Fig.4 Microstructures of Ti6Al4V-Fe alloy during continuous at $1^{\circ} \mathrm{C} / \mathrm{min}$ heating rate
(a) $838^{\circ} \mathrm{C}$
(b) $953^{\circ} \mathrm{C} \quad$ (c) $988^{\circ} \mathrm{C}$ 


\subsection{Phase transformed volume fraction}

Fig. 5 shows the schematic diagram of calculating the phase transition volume fraction curves. The lines $\mathrm{AN}$ and $\mathrm{BM}$ can be obtained by extending the linear expansion section of the thermal expansion curve. Then the point $\mathrm{O}$ is the intersection of $\mathrm{MN}$ and thermal expansion curve. Finally, the theoretical volume fraction of phase transition will be calculated $[\underline{9}, \underline{10}]$ as follow:

$$
f=\left(y_{m}-y_{o}\right) /\left(y_{m}-y_{n}\right)
$$

Where $\mathrm{f}$ is the volume fraction, $\mathrm{y}_{\mathrm{m}}, \mathrm{y}_{\mathrm{o}}, \mathrm{y}_{\mathrm{n}}$ denote the concentration of phase transition at end, middle, and begin stage, respectively $[\underline{11}, \underline{12}]$. As displayed in Fig. 6, the f-T curves show the similar "S" type trend. During the whole process of phase transition, we can clearly see that the phase transformation rate firstly increases, then decreases gradually and $t$ hen maintain almost unchanged at the high temperature. Furthermore, it is found that the transition curve is roughly "S" shape indicating that the $\alpha \rightarrow \beta$ transformation is controlled by the nucleation-growth mechanism $\underline{[13-15]}$.

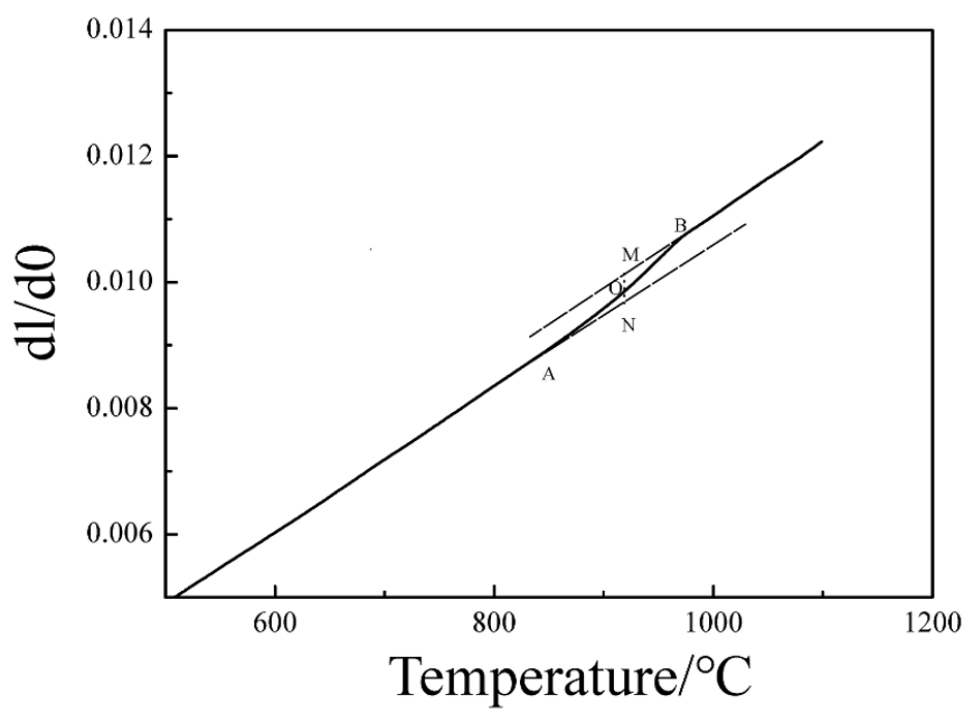

Fig.5 An example of calculating the phase transition kinetics volume fraction measured at $1^{\circ} \mathrm{C} / \mathrm{min}$ 


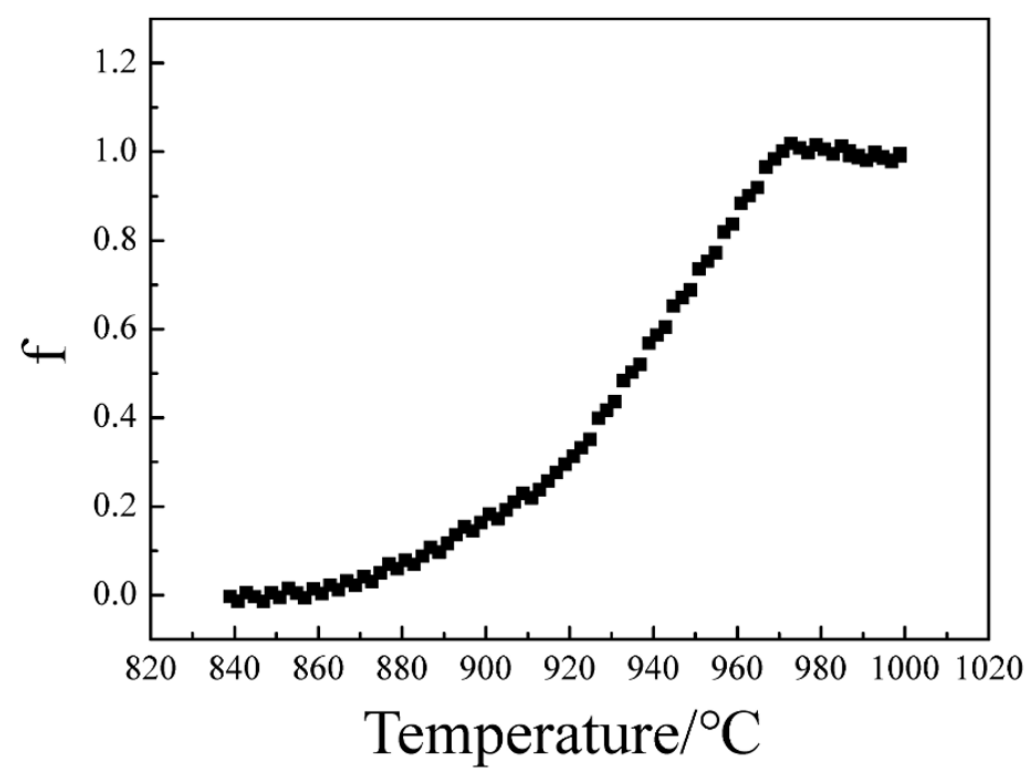

Fig.6 The $\beta$ phase transformed volume fraction of Ti6Al4V-Fe alloy

\section{Conclusion}

1. The $\alpha \rightarrow \beta$ phase transition occurs in the temperature range of $838-988^{\circ} \mathrm{C}$ during the continuous heating process at rate of $1^{\circ} \mathrm{C} / \mathrm{min}$ for Ti6Al4V-Fe alloy.

2. Phase transition temperature obtained by dilatometer method is very close to the metallographic method, which indicates that the phase transition temperature $\mathrm{T}_{\beta}$ obtained by the dilatometer method is true and reliable.

3. The $\alpha \rightarrow \beta$ phase transformed volume fraction curve shows the similar "S"-type trend indicating that $\alpha \rightarrow \beta$ transformation is controlled by the nucleation-growth mechanism.

\section{$\underline{\text { References }}$}

[1] Cui C X, Hu B M, Zhao L H, Materials \& Design, (2011) 1684-1691.

[2] Christian J W, Newnes, (2002) 1965-1963.

[3] Xin S W, TitaniumProgress, (201 Industry3) 12-15. 
[4] Wang Y, Kou H C, Chang H, Chinese Annals of Mathematics. 472(2009) 252-256

[5] Yao M, Harbin Institute of Technology. (2015) 157-160.

[6] Deng Z, Zhang X Y, Li Z Y, Chinese Annals of Mathematics. (2014) 23-26.

[7] Chang H, Zhou L, Wang X D, Journal of Aeronautical Materials. (2014) 37-42.

[8] Chen F W, Xu G L, Zhang X, Materials \& Design.130(2017) 16-22.

[9] Blazquez J, Conde C, Conde A, Acta Materialia. 53(2005) 2305-2308.

[10] Zhou Z B, Lai M J, Tang B, Materials Science and Engineering. 527(2010) 5100-5107.

[11] Sha W, Guo Z, Journal of alloys and compounds. 290(1999) L3-L7.

[12] Wang G N, Zhang X Y, Li Z Y, Chinese Journal of Nonferrous Metals. 24(2014) 1771-1776.

[13] Mittemeher E J, Cheng L, Schaaf P J V D, Metallurgical Transactions A. 19(1988): 92532.

[14] Liu F, Sommer F, Bos C, International Materials Reviews. 52(2013) 193-212.

[15] Mittemeijer E J, Van G A, Van D S P J, 17(1986) 1441-5. 